\title{
ORIGINAL
}

ARTICLES

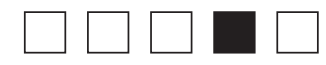

\section{Perceptions of Parenting Residents Among Family Medicine Residency Directors}

Laura E. Morris, MD, MSPH; Erik J. Lindbloom, MD, MSPH; Robin L. Kruse, PhD; Karla T. Washington, PhD, LCSW; Nikole J. Cronk, PhD; Heather L. Paladine, MD, MEd

\begin{abstract}
BACKGROUND AND OBJECTIVES: Parenting during residency is increasingly common, and resident parents face unique demands on their time and emotional and cognitive resources. Physicians at all levels of training perceive negative impacts of parenting on career and family life. Surveys of program directors (PDs) in other specialties reveal concern about performance and quality of life of parenting residents. The primary aims of this study were to examine family medicine PDs' perceptions of parenting residents' performance and the adequacy of parenting support structures.
\end{abstract}

METHODS: Data were collected from the 2017 Council of Academic Family Medicine (CAFM) Educational Research Alliance (CERA) Family Medicine Residency Program Directors survey. Directors provided the number and status of parenting residents and rated adequacy of parenting resources, resident performance, and impact of parenting on residents using a Likert scale. Results were compared between male/female PDs and male/female residents.

RESULTS: Response rate was $\mathbf{5 7 . 1 \%}$. Less than half of PDs reported adequate parenting support structures in their program (46\%). Over $40 \%$ of PDs reported that $81 \%-100 \%$ of female residents who take parental leave end up extending their residency training, the most common response category. PDs did not report gender-based differences in performance of parenting residents. PDs most often reported significantly worse well-being for female parenting residents but perceived improved well-being of male parents.

CONCLUSIONS: Less than half of family medicine PDs feel their program has adequate parenting resources. Female parenting residents commonly extend residency training. PDs perceive parenting negatively impacts well-being of female residents, but not male residents.

(Fam Med. 2018;50(10):756-62.)

doi: 10.22454/FamMed.2018.978635

$\mathbf{P}$ hysicians are becoming parents during or prior to their residency training at increasing rates. ${ }^{1} \mathrm{~A}$ recent survey of residents and fellows (three sites, 644 respondents across 269 programs) reported that nearly half either had children or were expecting their first child, and up to a third were planning to add to their family. ${ }^{2}$ Parenthood entails many responsibilities that place demands on parents' time as well as their cognitive and emotional resources. A recent survey of US physicians found that over $46 \%$ perceived that their career had a negative impact on their children. ${ }^{3}$ Another survey of residents at a Midwest academic institution reported significant neglect of hobbies, family life, and social life that was more pronounced among residents with children than those without. ${ }^{4}$

Previous research in family medicine and other specialties has documented resident dissatisfaction with factors associated with pregnancy and childbirth, including length of maternity leave, childcare arrangements, and duration of breastfeeding. ${ }^{1,5}$ The American Academy of Family Physicians' (AAFP) policy on parental leave during residency training makes general recommendations regarding management of a resident's schedule immediately surrounding the delivery or adoption of a child, but has no specific program requirements. ${ }^{6}$ In a prior study, we explored the positive and negative experiences of parenting family medicine residents at one institution beyond the newborn period. ${ }^{7}$ Results demonstrated that residents found parenting during residency to be stressful, and that they had feelings of guilt regarding inability to meet

From the University of Missouri School of Medicine, Department of Family and Community Medicine, Columbia, MO (Drs Morris, Lindbloom, Kruse, Washington, and Cronk), and Columbia University Vagelos School of Physicians and Surgeons, Center for Family and Community Medicine, New York, NY (Dr Paladine). 
the competing demands of parenthood and their career. A recent survey of childbearing general surgery residents revealed that over half of respondents agreed with statements of career dissatisfaction related to aspects of parenting. ${ }^{8}$

In spite of the increased demands placed on parenting residents and their own reported dissatisfaction, knowledge regarding the attitudes of family medicine residency program directors (PDs) related to resident parenthood is scant. Research in other specialties raises concern, such as a recent survey of general surgery PDs that revealed a lack of organized maternity and paternity leave policies. ${ }^{8}$ In the same study, the PDs also reported a perception that becoming a parent negatively impacted work performance of female residents, and that female residents' well-being was impacted more negatively than their parenting male peers. Similarly, a retrospective cohort study of internal medicine residents revealed that performance evaluation scores of female residents decreased following pregnancy. ${ }^{9}$ The same trend was not seen for male residents with pregnant partners. This trend is particularly salient given that women comprise a growing number of medical school graduates and resident physicians. ${ }^{10}$

The current study aims to describe the opinions and characteristics of family medicine residency PDs and residency programs regarding support structures for parenting residents. Additionally, we assessed the perceived impact of parenthood on male and female residents' performance (including extending residency) and well-being. We hypothesized that female family medicine PDs will promote support structures that enable residents to incorporate parenting into their training and report fewer female residents extending the duration of their residencies. We hypothesized that PDs' perception of somewhat or very adequate parenting support structures would be associated with fewer female residents extending their residency duration and less impact on residents' performance and well-being. We also hypothesized that PDs would perceive the impact of parenting on female residents to be more negative than the impact on male residents.

\section{Methods}

PDs of family medicine residency programs were questioned as part of a larger survey conducted by the Council of Academic Family Medicine Educational Research Alliance (CERA). The CERA survey methodology has been previously described. ${ }^{12}$ Our 10 additional questions were evaluated by the CERA steering committee for consistency with the overall subproject aim, readability, and evidence of reliability and validity. A subgroup of family medicine educators who did not comprise the target population pretested the questions, which were then modified based on pretesting feedback on flow, timing, and readability. The AAFP Institutional Review Board approved the project. Data were collected from September 2017 to October 2017.

The sampling frame for the survey was all Accreditation Council for Graduate Medical Education (ACGME)-accredited US family medicine residency program directors as identified by the Association of Family Medicine Residency Directors. Email invitations were delivered with the online program SurveyMonkey. Five follow-up emails encouraging nonrespondents to participate were sent after the initial email invitation. There were 549 program directors at the time of the survey. Thirteen had previously opted out of CERA surveys, and 14 additional email addresses were invalid. The final sampling frame was 522 .

\section{Survey Items}

The 67-item survey included a set of recurring general questions as well as a set of invited questions that changed with each survey. Recurring questions described residency program characteristics including PD gender and years in position, number of non-US graduates, whether the program was university-based or community-based, geographic region, and community size. We included 10 invited items querying PD opinions about support structures for parenting residents as well as the impact of parenting on residents' performance and well-being (see Appendix A at https://www.stfm. org/Portals/49/Documents/FMAppendix/Appendix-A-Morris-2018.pdf). We collected data regarding PD parenting status and the proportion of parenting residents in the program.

\section{Data Analysis}

Survey results were imported into SAS for Windows 9.4 (Cary, NC) for analysis. Simple frequencies of categorical variables were determined. Variables were compared using $\chi^{2}$ analysis. PDs' perceptions of the effects of parenting on female and male residents' performance and well-being were compared using the Wilcoxon rank sum test.

\section{Results}

Over half $(298,57.1 \%)$ of PDs returned their surveys. Most programs $(165,55.4 \%)$ were located in communities of 150,000 or more (Table 1). Most were academically affiliated $(78.9 \%)$. About one-third (35.6\%) had less than 19 residents, and just under half (47.7\%) had 19 to 31 residents. Almost half of all PDs reported that $20 \%$ or fewer residents in their program had children under the age of 18 years (46.6\%); $35.9 \%$ reported $21 \%$ to $40 \%$ parenting residents, and $13.4 \%$ reported that over $40 \%$ of their residents had children.

More than half $(56.7 \%)$ of PDs were men. Most PDs had children, with $60.4 \%$ reporting that they had children under 18 years and 28.9\% reporting that all their children were over age 18 years. Most PDs (62.8\%) had been in their current position for 5 years or less, and just over half $(51.7 \%)$ had spent 5 years or less as PDs.

Table 1 also shows the adequacy of parenting support structures as assessed by PDs. Less than half 
Table 1: Characteristics of Residency Programs and Program Directors, by Perceived Adequacy of Support for Parenting Residents (n [Row Percentage])

\begin{tabular}{|c|c|c|c|c|c|c|c|c|}
\hline \multirow[b]{2}{*}{ Characteristic (n Missing) } & \multirow[b]{2}{*}{ Total $\mathbf{n}^{\mathbf{a}}$} & \multicolumn{6}{|c|}{ Adequacy of Parental Support Structures (10) } & \multirow[b]{2}{*}{$P$ Value $^{\mathrm{b}}$} \\
\hline & & \multicolumn{2}{|c|}{$\begin{array}{l}\text { Very or Somewhat } \\
\text { Inadequate (\%) }\end{array}$} & \multicolumn{2}{|c|}{$\begin{array}{c}\text { Neither } \\
\text { Inadequate or } \\
\text { Adequate (\%) }\end{array}$} & \multicolumn{2}{|c|}{$\begin{array}{c}\text { Very or Somewhat } \\
\text { Adequate (\%) }\end{array}$} & \\
\hline \multicolumn{9}{|l|}{ Community size (2) } \\
\hline$<150,000$ & 131 & 45 & $(35.4)$ & 22 & $(17.3)$ & 60 & $(47.2)$ & .46 \\
\hline$\geq 150,000$ & 165 & 47 & $(29.6)$ & 35 & $(22.0)$ & 77 & $(56.2)$ & \\
\hline \multicolumn{9}{|l|}{ Program size (2) } \\
\hline$<19$ & 106 & 27 & $(26.5)$ & 25 & $(24.5)$ & 50 & $(49.0)$ & .43 \\
\hline $19-31$ & 142 & 50 & $(36.2)$ & 23 & $(16.7)$ & 65 & $(47.1)$ & \\
\hline$>31$ & 48 & 16 & $(34.8)$ & 8 & $(17.4)$ & 22 & $(47.8)$ & \\
\hline \multicolumn{9}{|l|}{ Academic affiliation } \\
\hline Academically affiliated & 235 & 76 & $(33.6)$ & 41 & $(18.1)$ & 109 & $(48.2)$ & \\
\hline Not affiliated & 63 & 18 & $(29.0)$ & 16 & $(25.8)$ & 28 & $(45.2)$ & .40 \\
\hline \multicolumn{9}{|l|}{ Residents with children $<18$ years $(12)$} \\
\hline $0 \%$ to $20 \%$ & 139 & 51 & $(36.7)$ & 30 & $(21.6)$ & 58 & $(41.7)$ & .27 \\
\hline $21 \%$ to $40 \%$ & 107 & 28 & $(26.2)$ & 19 & $(17.8)$ & 60 & $(56.1)$ & \\
\hline $41 \%$ to $100 \%$ & 40 & 13 & $(32.5)$ & 8 & $(20.0)$ & 19 & $(47.5)$ & \\
\hline \multicolumn{9}{|l|}{ Program director characteristics } \\
\hline \multicolumn{9}{|l|}{ Gender (11) } \\
\hline Female & 118 & 41 & $(35.7)$ & 28 & $(24.3)$ & 46 & $(40.0)$ & .096 \\
\hline Male & 169 & 50 & $(30.9)$ & 27 & (16.7) & 85 & $(52.5)$ & \\
\hline \multicolumn{9}{|l|}{ Parental status $^{9}$} \\
\hline Parent, youngest child $\leq 18$ years & 180 & 59 & $(33.0)$ & 34 & $(20.0)$ & 86 & $(48.0)$ & .022 \\
\hline Parent, youngest child $>18$ years & 86 & 27 & $(31.4)$ & 13 & $(15.1)$ & 46 & $(53.5)$ & \\
\hline Not currently a parent & 23 & 8 & $(34.8)$ & 10 & $(43.5)$ & 5 & $(21.7)$ & \\
\hline \multicolumn{9}{|l|}{ Years as PD, current position (2) } \\
\hline Up to 5 & 187 & 63 & $(35.0)$ & 38 & $(21.1)$ & 79 & $(43.9)$ & .31 \\
\hline More than 5 and up to 10 & 60 & 19 & $(33.3)$ & 11 & $(19.3)$ & 27 & $(47.4)$ & \\
\hline More than 10 & 49 & 11 & $(22.4)$ & 8 & $(16.3)$ & 30 & $(61.2)$ & \\
\hline \multicolumn{9}{|l|}{ Total years as PD (2) } \\
\hline Up to 5 & 154 & 50 & $(33.3)$ & 32 & $(21.3)$ & 68 & $(45.3)$ & .34 \\
\hline More than 5 and up to 10 & 79 & 29 & $(38.7)$ & 14 & $(18.7)$ & 32 & $(42.7)$ & \\
\hline More than 10 & 63 & 15 & $(24.2)$ & 11 & $(17.7)$ & 36 & $(58.1)$ & \\
\hline
\end{tabular}

aTotal $\mathrm{n}$ does not always match the sum of responses across the row due to missing values for adequacy of support structures.

${ }^{\mathrm{b}} P$ value for $\chi^{2}$ test.

(48.4\%) perceived that parenting support structures in their residency program were somewhat or very adequate; $32.5 \%$ perceived them as very or somewhat inadequate, and $19.1 \%$ perceived support as neither adequate or inadequate. Adequacy of support structures was not associated with community or program size, academic affiliation, the proportion of residents with children, PD gender, or years of experience of the PD. Adequacy of support structures was associated with the PD's parental status $(P=.022)$. Those who were not parents were least likely to judge their residency as having adequate support (21.7\%), while those whose children were all age 18 years or older were most likely to report adequate parenting support (53.5\%).

Over $40 \%$ of PDs responded that a high proportion (81\% to $100 \%$ ) of female residents who take parental 
leave at their program will extend residency as a result. One-third of PDs responded that a low proportion (0\% to $20 \%$ ) of female parents extend residency. Several factors were associated with extending residency (Table 2). A higher proportion of female residents extending their training was associated with location in an urban area $(P=.009)$, larger program size $(P=.046)$, and having a female PD $(P=.007)$ or having children under age 18 years $(P=.018)$. Perceived adequacy of parental support was not associated with residency extension $(P=.65)$.

While over two-thirds of PDs reported that being a parent did not affect the performance of either male or female residents, there was a significant difference based on resident gender (parenting had no effect on $79.6 \%$ of male vs $70.4 \%$ of female residents; $P=.006$ ). Worse performance of parenting male residents was reported by $7.4 \%$ of PDs and better performance by $13.1 \%$, while $15.8 \%$ of PDs reported worse performance of parenting female residents and $13.7 \%$ of PDs reported better performance. Adequacy of parenting support was associated with reporting higher proportions of female residents as having unchanged or better performance $(P=.021)$, but was not associated with reported performance of male residents (Table 3).

PDs most often reported that parenting decreased the well-being of female residents (45.0\%), while $20 \%$ reported no change and $34.9 \%$ reported increased well-being. In contrast, 23.5\% of PDs reported decreased well-being for male residents, no change for $34.4 \%$, and increased well-being for $42.1 \%$ ( $P<.0001$; Figure 1). There was no association between perceived adequacy of support structures and well-being of parenting residents (Table 3).

There was no association between the PDs' parental status and perceived performance of female or male residents, nor was there an association between the PDs' gender and the perceived performance of female or male residents. The PDs' parental status was not associated with their perception of how parenting affects the well-being of female or male residents. While PD gender was not associated with perceived change in well-being for male residents, female

Table 2: Proportion of Parenting Female Residents Who Extend Residency, by Residency Characteristics ( $\mathrm{n}$ [Row Percentage])

\begin{tabular}{|c|c|c|c|c|c|c|c|}
\hline \multirow[b]{2}{*}{ Characteristic (N Missing) } & \multicolumn{6}{|c|}{ Proportion Extending Residency (17) } & \multirow[b]{2}{*}{$P$ Value } \\
\hline & \multicolumn{2}{|c|}{$\begin{array}{c}0 \% \text { to } 20 \% \\
(n=95)\end{array}$} & \multicolumn{2}{|c|}{$\begin{array}{c}21 \% \text { to } 80 \% \\
(n=69)\end{array}$} & \multicolumn{2}{|c|}{$\begin{array}{c}81 \% \text { to } 100 \% \\
(n=117)\end{array}$} & \\
\hline$<150,000$ & 52 & $(43.0)$ & 30 & $(24.8)$ & 39 & $(32.2)$ & .009 \\
\hline$\geq 150,000$ & 43 & $(27.2)$ & 38 & $(24.0)$ & 77 & $(48.7)$ & \\
\hline \multicolumn{8}{|l|}{ Program size (2) } \\
\hline$<19$ & 43 & $(44.3)$ & 24 & $(24.7)$ & 30 & $(30.9)$ & .046 \\
\hline $19-31$ & 40 & $(29.2)$ & 33 & $(24.1)$ & 64 & $(46.7)$ & \\
\hline$>31$ & 11 & $(24.4)$ & 11 & $(24.4)$ & 23 & $(51.1)$ & \\
\hline \multicolumn{8}{|l|}{ Academic affiliation } \\
\hline Academically affiliated & 68 & $(30.6)$ & 55 & $(24.8)$ & 99 & $(44.6)$ & .067 \\
\hline Not affiliated & 27 & $(45.8)$ & 14 & $(23.7)$ & 18 & $(30.5)$ & \\
\hline \multicolumn{8}{|l|}{ Adequacy of support structures (10) } \\
\hline Somewhat or very inadequate & 33 & $(36.3)$ & 19 & $(20.9)$ & 39 & $(42.9)$ & .65 \\
\hline Neither inadequate or adequate & 17 & $(30.9)$ & 12 & $(21.8)$ & 26 & $(47.3)$ & \\
\hline Somewhat or very adequate & 45 & $(33.3)$ & 38 & $(28.1)$ & 52 & $(38.5)$ & \\
\hline \multicolumn{8}{|l|}{ PD gender (11) } \\
\hline Female & 34 & $(29.6)$ & 21 & $(18.3)$ & 60 & $(52.2)$ & .007 \\
\hline Male & 58 & $(37.4)$ & 45 & $(29.0)$ & 52 & $(33.5)$ & \\
\hline \multicolumn{8}{|l|}{ PD parental status (9) } \\
\hline Parent, youngest child $\leq 18$ years & 56 & $(32.2)$ & 34 & (19.5) & 84 & $(48.3)$ & .018 \\
\hline Parent, youngest child $>18$ years & 30 & $(35.7)$ & 30 & $(35.7)$ & 24 & $(28.6)$ & \\
\hline Not currently a parent & 9 & $(39.1)$ & 5 & $(21.7)$ & 9 & $(39.1)$ & \\
\hline
\end{tabular}

${ }^{\text {a }} P$ value for $\chi^{2}$ test. 
Table 3: Association of Perceived Adequacy of Support for Parenting Residents With Performance and Well-being of Residents (N [Row Percentage])

\begin{tabular}{|c|c|c|c|c|c|c|c|}
\hline \multirow[b]{2}{*}{ Resident Performance and Well-being (n Missing) } & \multicolumn{6}{|c|}{ Adequacy of Parental Support Structures (10) } & \multirow[b]{2}{*}{$P$ Value $^{\mathrm{a}}$} \\
\hline & \multicolumn{2}{|c|}{$\begin{array}{l}\text { Very or Somewhat } \\
\text { Inadequate }\end{array}$} & \multicolumn{2}{|c|}{$\begin{array}{l}\text { Neither Inadequate } \\
\text { nor Adequate }\end{array}$} & \multicolumn{2}{|c|}{$\begin{array}{l}\text { Very or Somewhat } \\
\text { Adequate }\end{array}$} & \\
\hline \multicolumn{8}{|l|}{$\begin{array}{l}\text { Performance of female residents who are parents } \\
\text { vs nonparent peers (14) }\end{array}$} \\
\hline Parents perform worse & 22 & $(48.9)$ & 9 & $(20.0)$ & 14 & $(31.1)$ & .021 \\
\hline No difference in performance & 54 & $(27.1)$ & 41 & $(20.6)$ & 104 & $(52.3)$ & \\
\hline Parents perform better & 16 & $(41.0)$ & 4 & $(10.3)$ & 19 & $(48.7)$ & \\
\hline \multicolumn{8}{|l|}{$\begin{array}{l}\text { Performance of male residents who are parents } \\
\text { vs nonparent peers (14) }\end{array}$} \\
\hline Parents perform worse & 10 & $(47.6)$ & 2 & $(9.5)$ & 9 & $(42.9)$ & .091 \\
\hline No difference in performance & 66 & $(29.3)$ & 50 & $(22.2)$ & 109 & $(48.4)$ & \\
\hline Parents perform better & 16 & $(43.2)$ & 3 & (8.1) & 18 & $(48.6)$ & \\
\hline \multicolumn{8}{|l|}{$\begin{array}{l}\text { How parenting changes the well-being of female } \\
\text { residents (13) }\end{array}$} \\
\hline Decreases & 47 & $(36.7)$ & 24 & $(18.8)$ & 57 & $(44.5)$ & .32 \\
\hline No change & 12 & $(21.1)$ & 14 & $(24.6)$ & 31 & $(54.4)$ & \\
\hline Increases & 33 & $(35.9)$ & 18 & $(32.1)$ & 48 & $(48.5)$ & \\
\hline \multicolumn{8}{|l|}{$\begin{array}{l}\text { How parenting changes the well-being of male } \\
\text { residents (12) }\end{array}$} \\
\hline Decreases & 29 & $(43.3)$ & 10 & (14.9) & 28 & $(41.8)$ & .16 \\
\hline No change & 25 & $(25.5)$ & 24 & $(24.5)$ & 49 & $(50.0)$ & \\
\hline Increases & 39 & $(32.5)$ & 22 & $(18.3)$ & 59 & $(49.2)$ & \\
\hline
\end{tabular}

${ }^{a} P$ value for $\chi^{2}$ test.

PDs were more likely to perceive decreased well-being for female residents $(55.6 \%)$ compared with male PDs $(37.1 \%)$ and less likely to perceive increased well-being for female residents $(27.8 \%$ vs $40.2 \%$, respectively; $P=.01$ ). All PDs rated the change in male residents' wellbeing after becoming a parent significantly higher than the change for female residents $(P<.0001)$. No program characteristics were associated with perceived performance or well-being for either female or male residents.

When asked in what way parenting most negatively impacts female residents, the majority of PDs reported no impact (52.1\%), followed by timeliness (16.9\%), increased burden on fellow residents (15.8\%), academic performance $(7.4 \%)$, and scholarly activity (4.9\%). Only eight PDs (2.8\%) endorsed patient care as the most negative impact. Similarly,
Figure 1: Program Directors' Perceptions of the Effects of Parenting on the Well-being of Male and Female Residents

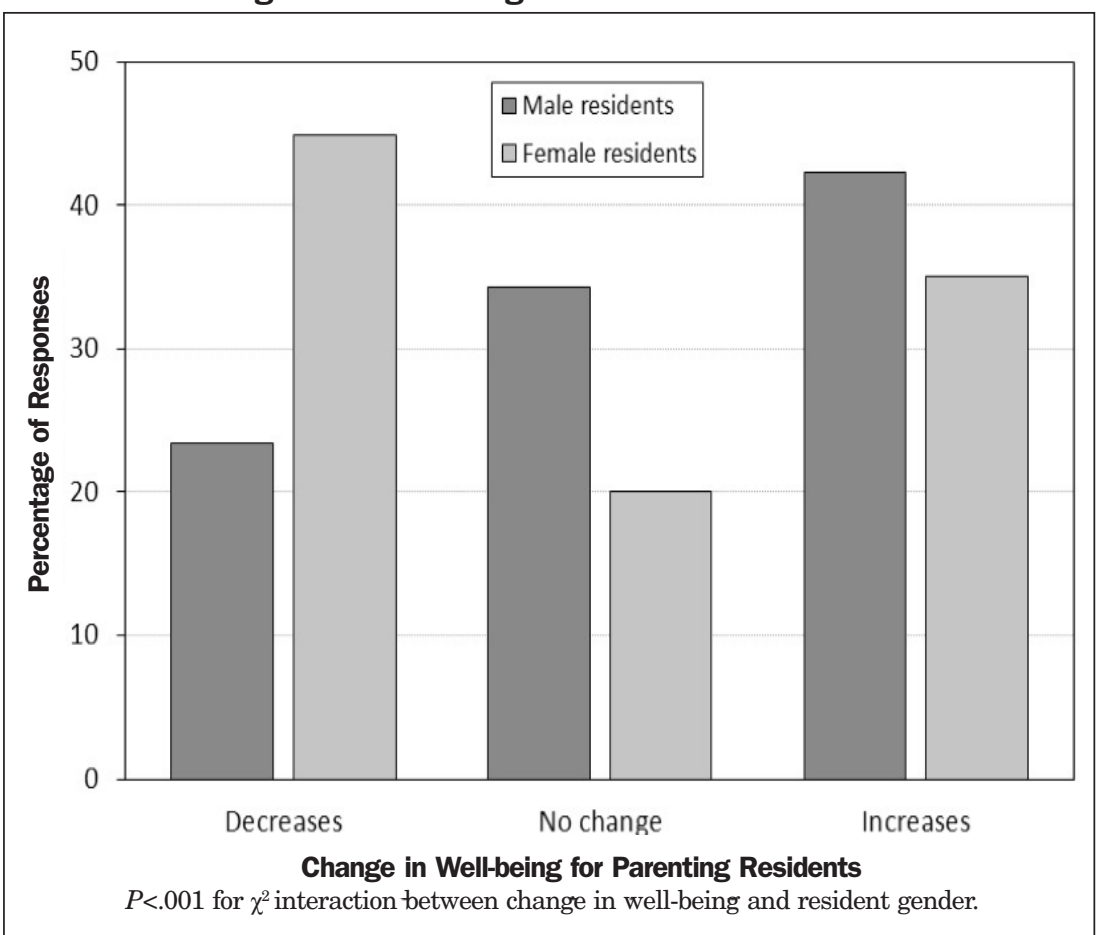


most PDs (67.1\%) reported no impact for men, followed by timeliness (12.9\%), increased burden on fellow residents $(6.6 \%)$, academic performance $(5.9 \%)$, and scholarly activity $(5.2 \%)$, with only six $(2.2 \%)$ endorsing patient care.

\section{Discussion}

Less than half of surveyed family medicine PDs feel that parenting support structures in their program, such as on-site or ill-child daycare, flexible work schedules, or breastfeeding/pumping facilities, are somewhat or very adequate. At the same time, $49 \%$ of PDs reported at least one in five residents in their program is parenting a child under the age of 18 years. Of female residents who become parents during residency, many extend residency training to accommodate their parental leave. The lack of association between parenting support and residency extension may reflect a supportive environment that encourages residents to take longer parental leave, or it may reflect an absence of structures within the residency that allow a new parent flexibility to return to work. It is unknown if parenting residents, particularly female residents, feel positively or negatively about extending residency. This discrepancy between the needs of parenting residents and the structures available to support them is similar to previous findings. ${ }^{8}$

PDs perceive that parenting during residency differentially affects male and female residents, and they report significantly worsened wellbeing in female parenting residents compared to their male counterparts. We found this effect was more pronounced for female relative to male PDs, reflecting a gender difference that may influence how PDs interact with parenting residents. Female PDs were also associated with higher proportions of female parenting residents extending their training. It is unknown if this reflects a supportive female PD encouraging parenting residents to bond with their infants or if some other factor may explain the difference. These gender discrepancies may warrant further investigation. In a previous singleinstitution report, internal medicine residents rated the performance of female peers in the postpartum period lower compared to their male peers who also became parents during residency. ${ }^{9}$ Family medicine PDs also perceive a differential impact of parenting on performance in male and female residents $(79.6 \%$ stated parenting had no impact on male residents compared to $70.4 \%$ reporting no effect on female residents; $P=.006)$. Growing evidence suggests this trend exists across specialties. In a recently published survey of obstetrics and gynecology PDs that did not differentiate between male and female residents, $82.8 \%$ of PDs thought becoming a parent negatively affected resident performance, and 50.9\% thought becoming a parent decreased resident well-being. ${ }^{13}$ General surgery PDs similarly report that having children negatively influences female residents' work compared to male residents $(61 \%$ vs $34 \%$ ) and that having children during residency somewhat or significantly diminishes well-being of female surgical residents more than male residents ( $31 \%$ vs $9 \%$ ). ${ }^{8}$

Given the number of residents who become parents during residency, anticipating and meeting the needs of this growing group is imperative to ensure family medicine training supports residents' well-being and facilitates adequate learning opportunities. Programs with well established support structures may be better able to respond to the needs of parenting residents, and may be able to use these features to improve the well-being and performance of female residents in particular. The lack of specific parental leave policies has been documented across specialty training programs and is associated with career dissatisfaction in general surgery residents. ${ }^{1,11,13}$ Further studies are warranted to elucidate the relationships between other specific support structures and resident performance and well-being.
Given the latitude of the AAFP policy on parental leave during residency training, further delineation of the types of resident programmatic supports available is needed. Specifically, understanding the perceptions of parenting residents of the adequacy of support structures and their own well-being may offer instruction and guidance for family medicine PDs.

This study has several limitations. First, the cross-sectional design may be vulnerable to recall bias. Nonresponse bias may have an effect if PDs who chose not to answer parenting questions differed from those who did respond. PDs may have felt pressured to respond to items rating residency characteristics or resident performance in a socially desirable way, or may have altered their responses because of a perception of personal accountability. The response rate of $57.1 \%$ limits generalizability, although responses were well distributed across demographic categories and similar to previous CERA survey response rates. This survey was limited to PDs, and these results do not reflect the current opinions of parenting or nonparenting residents.

It is unlikely that the proportion of parenting family medicine residents will decline. The results of this study can inform PDs and other residency administrators of how parenting during residency affects resident well-being, and how more adequate support structures are needed. Further study of the impact of parenting policy changes on residents' well-being and performance is indicated.

CORRESPONDING AUTHOR: Address correspondence to Laura Morris, MD, MSPH, University of Missouri Family Medicine Residency, Medical Science Building, MA303, One Hospital Drive, Columbia, MO 65212. 573-882-9099. morrislau@health.missouri.edu.

\section{References}

1. Hutchinson AM, Anderson NS III, Gochnour GL, Stewart C. Pregnancy and childbirth during family medicine residency training. Fam Med. 2011;43(3):160-165.

2. Blair JE, Mayer AP, Caubet SL, Norby SM, O'Connor MI, Hayes SN. Pregnancy and parental leave during graduate medical education. Acad Med. 2016;91(7):972-978. 
3. Shanafelt TD, Hasan O, Hayes S, et al. Parental satisfaction of U.S. physicians: associated factors and comparison with the general U.S. working population. BMC Med Educ. 2016;16(1):228.

4. Mahmood S, Jackson R, Zhao YD, Oxentenko AS, Ali T, Wong JG. Assessment of work-life balance of resident physicians. Am J Med Sci. 2015;350(6):519-520.

5. Holliday EB, Ahmed AA, Jagsi R, et al. Pregnancy and Parenthood in Radiation Oncology, Views and Experiences Survey (PROVES) Results of a Blinded Prospective Trainee Parenting and Career Development Assessment. Int J Radiat Oncol Biol Phys. 2015;92(3):516524

6. Morris L, Cronk NJ, Washington KT. Parenting during residency: providing support for $\mathrm{Dr}$ Mom and Dr Dad. Fam Med. 2016;48(2):140144.

7. American Academy of Family Physicians. Parental Leave During Residency Training. https://www.aafp.org/about/policies/all/ parental-leave.html. Accessed July 31, 2018.
8. Sandler BJ, Tackett JJ, Longo WE, Yoo PS Pregnancy and parenthood among surgery residents: results of the first nationwide survey of general surgery residency program directors. J Am Coll Surg. 2016;222(6):1090-1096.

9. Krause ML, Elrashidi MY, Halvorsen AJ, McDonald FS, Oxentenko AS. Impact of pregnancy and gender on internal medicine resident evaluations: A retrospective cohort study. J Gen Intern Med. 2017;32(6):648-653.

10. Association of American Medical Colleges. Table B-2: Total graduates by U.S. medical school, sex, and year, 2010-2011 through 2014-2015. In: FACTS: Applicants, Matriculants, Enrollment, Graduates, MD-PhD, and Residency Applicants Data. https://www.aamc.org/data/ facts/enrollmentgraduate/148670/total-gradsby-school-gender.html. Accessed August 21, 2018.

11. Rangel EL, Lyu H, Haider AH, Castillo-Angeles M, Doherty GM, Smink DS. Factors Associated With Residency and Career Dissatisfaction in Childbearing Surgical Residents. JAMA Surg. 2018. [online first]
12. Mainous AG III, Seehusen D, Shokar N. CAFM Educational Research Alliance (CERA) 2011 Residency Director survey: background, methods, and respondent characteristics. Fam Med. 2012;44(10):691-693.

13. Hariton E, Matthews B, Burns A, Akileswaran C, Berkowitz LR. Pregnancy and Parental Leave among Obstetrics and Gynecology Residents: Results of a Nationwide Survey of Program Directors. Am J Obst Gyn. 2018;219(2):199.e1-199.e8. 